\title{
Physiotherapy Students' Use of Online Technology as part of their Learning Practices: A Case Study
}

\begin{abstract}
The relevance of non-technical skills have long been acknowledged as important components of clinical learning, and there is evidence that integrating technology canfacilitate their development by encouraging reflection, and by enhancing communication and reasoning. However, effectively integrating technology into learning practices must take the contextual needs of students into consideration. The aim of this study was to determine what online tools undergraduate physiotherapy students at one South African university are familiar with, and how they use them as part of their learning practices.

The case study was conducted in a university physiotherapy department in the Western

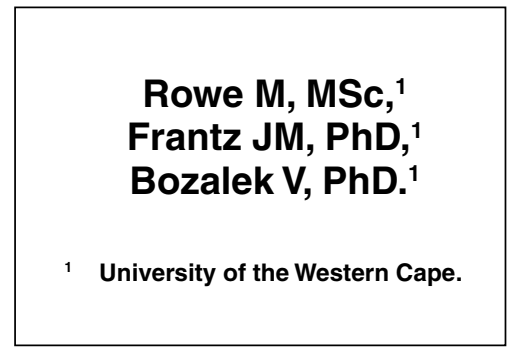
Cape during 2010. A cross-sectional, descriptive design used a survey to obtain quantitative and qualitative data from participants, and a pilot study was conducted to test the reliability of the instrument. All ethical considerations were adhered to.

Seventy six percent of participants had access to the internet at home, and $93 \%$ of them belonged to a social network, although fewer than half used it for their studying. Few students reported using the internet for more than information retrieval but reported wanting to use it for enhanced communication with lecturers. Almost all respondents believed that lectures were a useful way to learn. However, $61 \%$ added that integrating online learning activities with lectures could have value.

Integrating technology into healthcare education has the potential to develop non-technical skills that are relevant for clinical practice. However, this group of students currently lack the experience and insight to use technology effectively as part of their learning practices. Educators must take cognisance of the educational and contextual needs of students if they wish to integrate technology into clinical teaching.
\end{abstract}

KEY WORDS: PHYSIOTHERAPY STUDENTS, HEALTHCARE EDUCATION, TECHNOLOGY ENABLED LEARNING, SOCIAL NETWORKS

\section{INTRODUCTION}

While the physiotherapy profession continues to emphasise evidence-based practice, it is vital that we not lose focus on the non-technical skills that are required for effective clinical practice. The importance of reflection and other generic skills in the development of practice knowledge in health professionals is well documented (Higgs et al, 2004). These non-technical skills include, among others, reflective thinking, interpersonal skills, critical evaluation of practice, accountability, clinical reasoning, bridging theory and practice, and articulating rationales for treatment (Higgs et al, 1991). The use of reflection to promote clinical reasoning has shown that when educators use their expertise to focus, guide and direct students in clinical practice, learning outcomes are positively affected (Murphy, 2004).
Productive learning activities that have been shown to be effective in healthcare education include individual contact, discussion and feedback (Ernstzen \& Bitzer, 2009; Windish et al, 2005). In addition, the integration of critical crossfield outcomes into all South African curricula has highlighted the importance of generic graduate attributes. These include the ability to access and critically evaluate information, and to work effectively with others (South African Qualifications Authority, 2011). It is therefore evident that non-technical skills have an important role to play in the development of competent healthcare professionals.

However, the majority of educators within medical education still make use of teaching activities that "...knowingly fail to change...behavior" (Cohen, 2004, pg. 2). In addition, many medical teachers have little formal qualification in teaching and therefore teach as they were taught (Hurst, 2004). If clinical teaching is to make an impact on improving patient care, there is a need to incorporate more interactive approaches to teaching and learning activities (Graffam, 2007). There is increasing evidence that Technology Enhanced Learning (TEL) has the potential to facilitate a more active approach to

\footnotetext{
Corresponding Author:

M. Rowe

Department of Physiotherapy

University of the Western Cape

Private Bag X17

Bellville

7530

South Africa

E-mail: mrowe@uwc.ac.za
} 
teaching and learning within healthcare education. Integrating technology into healthcare education has been shown to improve professional education and student support, mainly through better communication and increased access to information (Rowe \& Struthers, 2009). In addition, the use of online collaborative environments like blogs ${ }^{1}$ and wikis ${ }^{2}$ have the potential to encourage reflection and clinical reasoning in professional practice among undergraduate physiotherapy students (Boulos et al, 2006; Hartshorne \& Ajjan, 2009; Ladyshewsky \& Gardner, 2008; Mori et al, 2008). Blending technology into healthcare education has also been shown to help develop interprofessional team process skills, team dynamics, decision-making and conflict resolution skills (Carbonaro et al, 2008). Finally, there is evidence that students who displayed deep learning traits when using TEL have also been shown to perform better in assessments of their clinical skills (Gormley et al, 2009). This may be because blending technology and face-to-face engagement has been shown to help bridge the gap between theory and its application in practice (Davies et al, 2005).

There is therefore increasing evidence that the integration of online technologies into healthcare education can be effective in facilitating learning environments that encourage the development of non-technical skills such as collaboration, reflection and knowledge sharing. However, there are many challenges involved in the process of integrating technology into teaching and learning, including the fact that educators must model the behaviour they expect from students (Gray \& Tobin, 2010). The effectiveness of using Information and Communication Technology (ICTs) in teaching and learning lies not in its presence in the curriculum but rather in how it is deployed in order to mediate the learning process (Postholm, 2007). In addition, many South African students use ICTs merely for content acquisition and simple research, rather than taking advantage of the many possibilities for enhanced communication (Czerniewicz \& Brown, 2005; Rowe $\&$ Struthers, 2009). Even though there have been many attempts to make use of collaborative online tools to facilitate health professional education, these have often been unsuccessful. This has been largely because the contextual working and learning needs of students were not taken into consideration during implementation, and support was not provided (Sandars et al, 2007). Finally, South African students from lower socio-economic groups have more difficulty getting online when they are not on campus, placing them at a greater disadvantage than they already experience (Czerniewicz, et al, 2009). These are important considerations to be aware of, especially in light of the fact that the university in which this study was conducted places considerable value on the integration of technology into teaching practice (University of the Western Cape, 2009). Therefore, integrating TEL practices into healthcare education will require a change in culture among clinical educators, who will have to become familiar with online environments if they are to engage with their students in these spaces.

It seems clear that TEL strategies can be used to develop non-technical attributes that can play an important role in healthcare education. However, before healthcare programmes can integrate technology into the curriculum, it is important to understand if and how students already use technology as part of their studies. The aim of this case study was to determine what online tools this group of South African undergraduate physiotherapy students were familiar with, and whether they used those tools as part of their learning practices. The results of this study will be used to inform the development of innovative teaching strategies within this undergraduate physiotherapy programme.

\section{METHOD}

\section{Research setting and sample}

This case study was conducted as part of a larger research project within the physiotherapy department at the University of the Western Cape during 2010, among all undergraduate physiotherapy students $(n=131)$.

\section{Study design}

A cross-sectional, descriptive design was used to obtain both quantitative and qualitative data by means of a survey questionnaire with closed- and openended questions. The questionnaire was developed using the study objectives and a review of relevant literature (Boynton \& Greenhalgh, 2004; Hargittai, 2010). Closed-ended questions included Yes / No responses and a visual analogue and five point Likert scale. These were used to identify participants' learning preferences and their comfort when engaging in online activities. Openended questions were used to provide context and depth to the closed-ended responses. The questionnaire made use of five categories, including; Internet access, Use of online tools, Learning preferences, Attitudes towards teaching practices, and Demographic information. A pilot study was conducted with participants from the $2^{\text {nd }}$ year class $(n=30)$ in order to test the reliability of the instrument. A test-retest analysis with a one week gap between tests demonstrated that the instrument was reliable (Cronbach's alpha $=0.74$ ). Student feedback and analysis of the results led to improvement of the instrument by removing ambiguity and standardising terminology. Finally, consultation with two experienced researchers in the field of healthcare education was used to improve face and content validity.

1 A blog is a personal webpage that allows users to post entries in reverse chronological order and moves older entries into an archive, much like a journal (Quiggin, 2006)

2 Wikis are websites that are able to be edited by anyone. Users can create, edit and delete pages and content using a simple text-editing interface (Duffy \& Bruns, 2006). 


\section{Procedure}

The survey was administered to all registered students in the remaining three undergraduate classes when they were on campus, taking into account the clinical rotations of the students. The $4^{\text {th }}$ year students were surveyed during the second term, while the $1^{\text {st }}$ and $3^{\text {rd }}$ year surveys were completed in the third term. The researcher was present during the surveys in order to address any questions that might arise. Data were captured using double entry to ensure consistency and accuracy, and was analysed descriptively. Responses to openended questions were analysed thematically by the first and second authors, until consensus was reached.

\section{Ethical considerations}

The project was approved by the university's Ethics Committee (registration number: 09/8/16), and permission to conduct the survey was obtained from the Head of Department. Each questionnaire was accompanied by an information sheet explaining the background and reason for conducting the survey. Students gave written, informed consent following an opportunity to clarify the study details. Participation in the survey was voluntary and students were informed that they could withdraw at any time with no negative consequences. Anonymity of participants was insured by not gathering personally identifiable information and all data was kept confidential and secure.

\section{RESULTS}

One hundred and thirty one questionnaires were distributed among all undergraduate students in the department. The sample included all students who completed and submitted the questionnaire $(\mathrm{N}=109)$, indicating a response rate of $83 \%$. ${ }^{3}$ Seventy three percent $(n=80)$ of the respondents were female. Response by year of study and gender can be seen in Table 1.

\section{Access to computers and the internet}

Eighty three students (76\%) had internet access at home and the other respondents reported accessing the internet from internet cafés, friends' homes, family members' homes and parents' workplaces. All students had access to the internet on campus. Of the students who connected to the internet from home, $50(60 \%)$ used broadband, 23 (28\%) used a $3 \mathrm{G}$ modem, and 10 (12\%) used a dialup modem. Seventy one (65\%) students reported using a desktop computer to access the internet, 59 (54\%) used a laptop, and 77 (71\%) used phones. ${ }^{4}$

\section{Use of collaborative online tools and services}

Of the 89 respondents (82\%) who reported using the internet during the learning process, $75(84 \%)$ reported that they used it mainly to retrieve information. One hundred and one students (93\%) reported belonging to a social network $^{5}$, with 27 checking it hourly, and 59 checking it at least once a day. Fewer than half of the 101 students who reported belonging to a social network (49\%) used it as part of their studying. The students who did use their social networks as part of their studies used it for either administrative tasks (e.g. confirming test dates), getting information (e.g. content for assignments), asking for help and to a limited extent, discussion. The following three quotes are used to give an example of the areas in which students used social networks:
"To get information and connect with people that can help me if I don't know something”,

"...inform or be informed of campus life e.g. Test content covered, dates and venues"

"Asking questions and sharing information"

Students who did not use social networks as part of their learning used reasoning that fell into four main categories: it was distracting, it was for socialising and not studying, difficulty with access and finally, that they didn't know how their social networks would be useful for studying. The following three quotes are used as examples:

"It interferes with your studies and takes your concentration and focus off work"

"... I study at home and internet isn't always available"

"The social network cannot help me with my studies its only there to communicate with my friends"

The following table (Table 2) highlights online activities that students reported engaging in as part of their studies, as well as socially. The list was compiled following a review of the literature to determine common online activities.

Table 2 demonstrates that this group of students use the internet mainly to consume content. However, almost half of them also create content by sharing photos with each other. There were no data on how often students engaged with each other around shared content.

Table 1: Student responses by year of study $(\mathrm{N}=109)$

\begin{tabular}{|l|l|l|l|}
\hline Year & \multicolumn{2}{|c|}{ No. of responses } & Response by class \\
\hline & Female & Male & \\
\hline 1 & $35(32 \%)$ & $14(13 \%)$ & $49(45 \%)$ \\
\hline 2 & Included in pilot study, excluded from main study & N/A \\
\hline 3 & $22(20 \%)$ & $6(6 \%)$ & $28(26 \%)$ \\
\hline 4 & $23(21 \%)$ & $5(5 \%)$ & $28(26 \%)$ \\
\hline
\end{tabular}

Note: 4 respondents did not record their gender

3 All percentages have been rounded to the nearest whole number.

4 Students were able to specify multiple devices for connecting to the internet

5 Students were not asked which network they used, although Facebook and Mxit were identified most often in the open-ended responses 
Table 2: Participants' engagement with common online activities $(\mathrm{N}=109)$

\begin{tabular}{|l|l|}
\hline Online activity & $\mathbf{n}(\%)$ \\
\hline Watched a video & $62(57 \%)$ \\
\hline Read something on Wikipedia & $55(50 \%)$ \\
\hline Uploaded photos & $47(43 \%)$ \\
\hline Uploaded a video & $12(11 \%)$ \\
\hline Created a blog post & $10(9 \%)$ \\
\hline Edited Wikipedia & $6(6 \%)$ \\
\hline
\end{tabular}

Table 3: Participants' understanding of common online tools $(\mathrm{N}=109)$

\begin{tabular}{|l|l|l|l|}
\hline Online tool & $\begin{array}{l}\text { Correct idea } \\
\mathbf{n}(\%)\end{array}$ & $\begin{array}{l}\text { Basic idea } \\
\mathbf{n}(\%)\end{array}$ & $\begin{array}{l}\text { No idea } \\
\mathbf{n}(\%)\end{array}$ \\
\hline Blog & $25(23 \%)$ & $24(22 \%)$ & $60(55 \%)$ \\
\hline Podcast & $8(7 \%)$ & $6(6 \%)$ & $95(87 \%)$ \\
\hline Wiki & $1(1 \%)$ & $16(15 \%)$ & $92(84 \%)$ \\
\hline
\end{tabular}

Table 4: Participants' personal learning preferences $(\mathrm{N}=109)$

\begin{tabular}{|l|l|}
\hline Learning preference & $\mathbf{n}(\%)$ \\
\hline Lectures & $101(93 \%)$ \\
\hline Pictures and graphics & $84(77 \%)$ \\
\hline Printed text & $79(72 \%)$ \\
\hline Discussion with others & $76(70 \%)$ \\
\hline Study groups & $35(32 \%)$ \\
\hline Cramming & $33(30 \%)$ \\
\hline
\end{tabular}

Note: students were able to select multiple options

Table 3 highlights the fact that more students had a good idea of what "blogging" means and is probably the result of a series of assignments that were run in the department during 2010, in which students participated in reflective blogging assignments within a social network. One participant suggested that wikis were sources of "unreliable information", and another that they were "excellent resources". Twelve participants $(11 \%)$ understood that podcasts were somehow related to online audio or video files but were not clear on what the relationship was.

Table 4 (see above) presents students' learning preferences.

Table 4 highlights that almost all respondents $(n=101,93 \%)$ believed that lectures are still a useful way to learn, although 67 of them (61\%) added that integrating online learning activities with lectures could have value. One of the main areas in which they wanted to see further use of online tools was for additional means of communicating with lecturers. Students requested greater use of email, cellphones, social networks and blogs.

\section{DISCUSSION}

While the lack of access to computers and the internet among South African university students is a real problem (Czerniewicz \& Brown, 2005), this particular group seemed to have relatively better access than most. More than 75\% had access to the internet at home and made use of it via desktop and laptop computers, as well as cellphones. The high number of respondents (71\%) who accessed the internet through their mobile devices was not surprising, considering that a previous study in the same department found that $84 \%$ of students were active on MXit, a mobile communication service (Rowe, 2009). However, even though most of the participants had internet access at home, many of them lacked experience in using ICTs. Their responses highlighted a poor understanding of several technologies commonly used to develop collaborative and reflective skills, namely wikis, blogs and podcasts (Boulos et al, 2006). The online activities that respondents were most familiar with included reading Wikipedia and watching videos. This would suggest that these participants used the internet mainly for consumption of content, rather than collaboration and discussion.

Even though more than $90 \%$ of participants belonged to a social network, fewer than half used them as part of their learning activities. Of the participants who did use their social networks as part of their studies, most used it for curriculum administrative tasks and for getting course-related information (e.g. sharing test dates). This is in keeping with the results of a national study in 2007, which found that South African physiotherapy students mainly used computers and the internet to gather information rather than to seek support through enhanced communication with peers and lecturers (Rowe \& Struthers, 2009). If educators wish to make use of ICTs to develop non-technical skills like reflection and reasoning, they will have to encourage activities that incorporate discussion, collaborative work and reflective engagement.

Students in this study expressed a preference for learning activities that make use of graphical and textual representations of information, as well as formats that involve discussion. The use of ICTs can have a significant impact on learners who express a preference for visual engagement as part of their learning. The ability to embed multimedia within collaborative online spaces means that students can not only share information in the form of images and video, but can also create asynchronous conversations and discussion around it. However, even though these students reported preferences for visual and collaborative learning strategies, they didn't seem to realise that social networks could facilitate these aspects of their learning 
practice. Instead, they used the internet and their social networks to gather and share administrative information and to consume content.

While most of these participants valued lectures as useful ways of learning they also wanted to add online learning activities and additional channels of communication to the curriculum, including greater use of cellphones. Together with the fact that $71 \%$ of respondents reported using their mobile devices to access the internet, this would seem to indicate that this group of students are prepared for synchronous learning when off campus. This is a positive result, especially in light of the fact that other students have also reported valuing communication as a an important component of learning in clinical contexts (Ernstzen \& Bitzer, 2009). One concern in terms of students' learning preferences is that more than a third of this cohort believed that "cramming" was an appropriate learning strategy. In fact, students' memorising of content is actually an indicator of poor assessment practices from lecturers, as students are not required to develop higher order thinking skills in order to pass (Brown et al, 1997). In contrast, ICTs have been shown to encourage the development of collaborative, reflective and reasoning skills that may help students move away from memorising content. If assessment does indeed drive learning then educators must ensure that their use of ICTs fosters the development of the non-technical skills that are relevant for clinical practice, rather than merely challenges students to find content.

\section{CONCLUSION, LIMITATIONS AND RECOMMENDATIONS}

The fact that $73 \%$ of participants in this case study were female indicates that there might be gender bias present in the results. In addition, almost half of the participants were in their first year of study, suggesting that they may not yet have developed the necessary skills to make use of more sophisticated learning strategies. The survey may also have yielded more interesting data if there had been more open-ended questions. The results of this study would seem to indicate that even though the majority of these physiotherapy students have access to the internet, many lack the deeper understanding of ICTs that would allow them to make effective use of it as part of their studies. Integrating technology into teaching and learning practice has the potential to help develop the non-technical skills that are so important in clinical practice. However, this particular group of students currently lack the experience and insight to make effective use of online technologies as part of their clinical learning experiences. In addition, educators wishing to make use of technology as part of their teaching practices, must take care to implement it in ways that take cognisance of the educational and contextual needs of the learners.

\section{ACKNOWLEDGEMENTS}

The authors acknowledge the National Research Foundation for providing funding that helped make this research project possible. We would also like to thank the following students for their contributions in terms of data collection and capture: N. Davids, M. Hayat, A, Karodia \& Z. Sablay.

\section{REFERENCES}

Boulos MNK, Maramba I, Wheeler S 2006. Wikis, blogs and podcasts: a new generation of Web-based tools for virtual collaborative clinical practice and education. BMC medical education, 6(41): 8

Boynton PM, Greenhalgh T 2004. Selecting, designing, and developing your questionnaire. British Medical Journal, 328: 1312-1315

Brown G, Bull J, Pendlebury M 1997. Assessing Student Learning in Higher Education. London and New York: Routledge. ISBN: 0415162262

Carbonaro M, King S, Taylor E, Satzinger F, Snart F, Drummond J 2008. Integration of e-learning technologies in an interprofessional health science course. Medical Teacher, 30(1): 25-33

Cohen JC 2004. Instituting improvement in medical education. Association of American Medical Colleges Reporter, 13(11): 2

Czerniewicz L, Williams K \& Brown C 2009. Students make a plan: understanding student agency in constraining conditions. Alt-J, 17(2): $75-88$
Czerniewicz L, Brown C 2005. The uses of information and communication (ICT) in teaching and learning in South African higher education practices in the Western Cape. Perspectives in Education 23(4): 1-18

Davies A, Ramsay J, Lindfield H, Couperthwaite J 2005. A blended approach to learning: added value and lessons learnt from students' use of computer-based materials for neurological analysis. British Journal of Educational Technology; 36(5): 839-849

Duffy P, Bruns A 2006. The use of blogs, wikis and RSS in education: A conversation of possibilities. Learning and Teaching Conference, 31-38

Ernstzen DV, Bitzer E 2009. Physiotherapy students' and clinical teachers' perceptions of clinical learning opportunities: A case study. Medical Teacher, 31: 102-115

Gormley GJ, Collins K, Boohan M, Bickle IC, Stevenson M 2009. Is there a place for e-learning in clinical skills? A survey of undergraduate medical students' experiences and attitudes. Medical Teacher, 31: e6-e12

Graffam B 2007. Active learning in medical education: strategies for beginning implementation. Medical teacher, 29(1): 38-42

Gray K, Tobin J 2010. Introducing an online community into a clinical education setting: a pilot study of student and staff engagement and outcomes using blended learning. BMC Medical Education, 10(6): 1-30

Hargittai, E. (2010). Digital Na(t)ives? Variation in Internet Skills and Uses among Members of the "Net Generation." Sociological Inquiry, 80(1): 92-113

Hartshorne R, Ajjan H 2009. Examining student decisions to adopt Web 2.0 technologies: theory and empirical tests. Journal of Computing in Higher Education, 21(3): 183-198

Higgs J, Glendinning M, Dunsford F, Panter J 1991. Goals and components of clinical education in the allied health professions. In: Proceedings of the 11th International Congress of the World Confederation for Physical Therapy, London. pp. 305-307

Higgs J, Richardson B, Dahlgren MA 2004. Developing Practice Knowledge for HealthProfessionals. Butterworth-Heinemann, Tottenham Court Road, London, W1T 4LP. ISBN: 0750654295

Hurst JW 2004. The overlecturing and underteaching of clinical medicine. Internal Medicine, 164: 1605-1608 
Ladyshewsky RK, Gardner P 2008. Peer assisted learning and blogging: A strategy to promote reflective practice during clinical fieldwork. Australasian Journal of Educational Technology, 24(3): 241-257

Mori B, Batty HP, Brooks D 2008. The feasibility of an electronic reflective practice exercise among physiotherapy students. Medical teacher, 30: $232-238$

Murphy JI 2004. Using focused reflection and articulation to promote clinical reasoning: an evidence-based teaching strategy. Nursing Education Perspectives, 25(5): 226-231

Postholm MB 2007. The advantages and disadvantages of using ICT as a mediating artefact in classrooms compared to alternative tools. Teachers and Teaching: theory and practice,13(6): 587-599
Quiggin J 2006. Blogs, wikis and creative innovation. Journal of Cultural Studies, 9(4): 481-496

Rowe M 2009. Knowledge and attitudes regarding the use of social software in a physiotherapy department. Journal of Community and Health Sciences, 4(1): 1-7

Rowe M, Struthers P 2009. The use of information and communication technology by South African physiotherapy students. South African Journal of Physiotherapy, 65(3): 32-37

Sandars J, Langlois M, Waterman H 2007. Online collaborative learning for healthcare continuing professional development: a cross-case analysis of three case studies. Medical Teacher, 29(1): 9-17

South African Qualifications Authority 2011. Glossary of terms: critical cross-field outcomes. Accessed 18 October, 2011 from http://www.saqa. org.za/show.asp? include=about/glossary/terms.htm
University of the Western Cape 2009. Implementation plan for UWC Teaching and Learning Strategy 2010-2014. Policy document

Windish DM, Price EG, Clever SL, Magaziner JL, Thomas PA 2005. Teaching Medical Students the Important Connection between Communication and Clinical Reasoning. Journal of General Internal Medicine, 20(12): 1108-1114

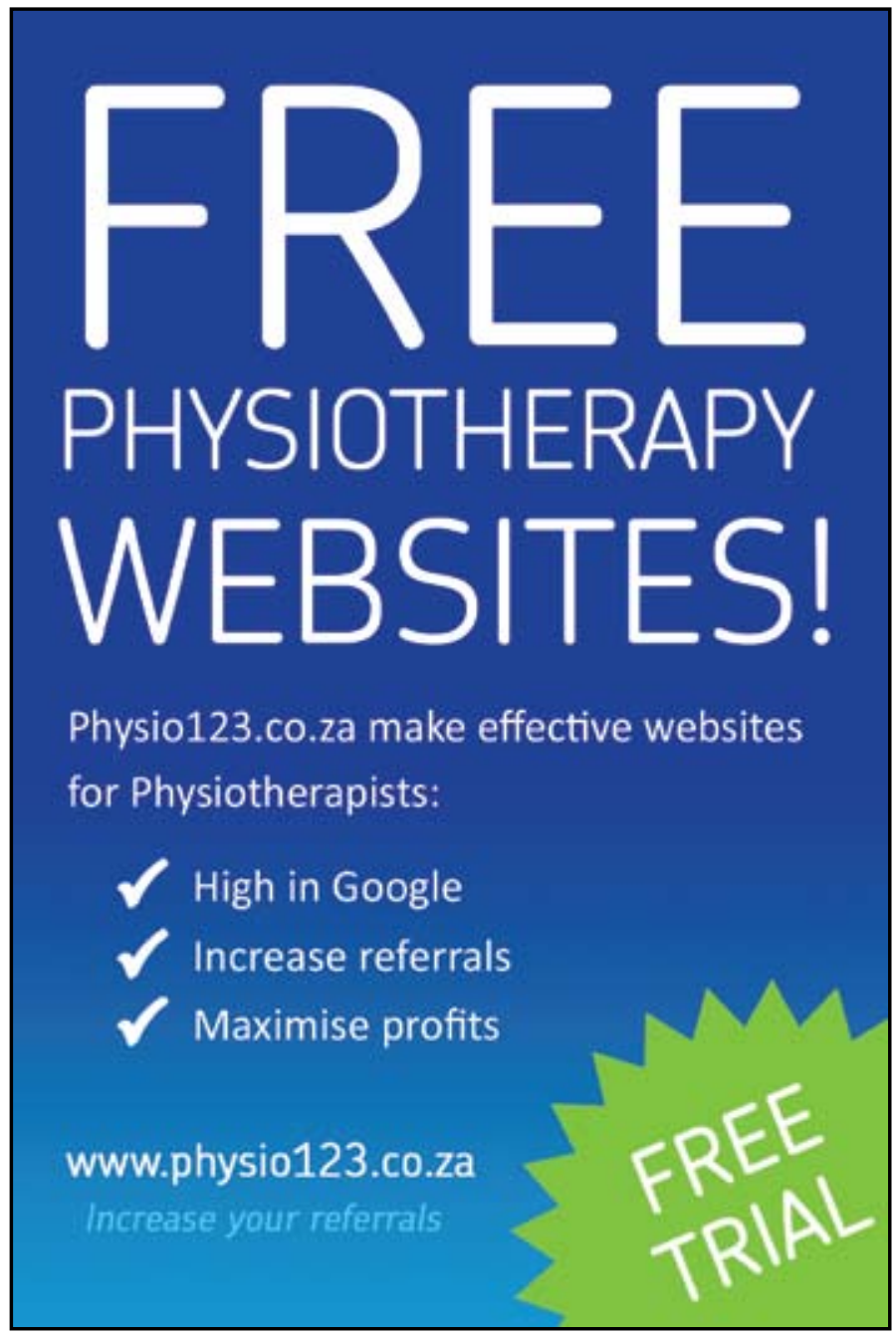

\section{Nature's Massage Cream}

Designed by a physio for physios patient satisfaction I practice profitability

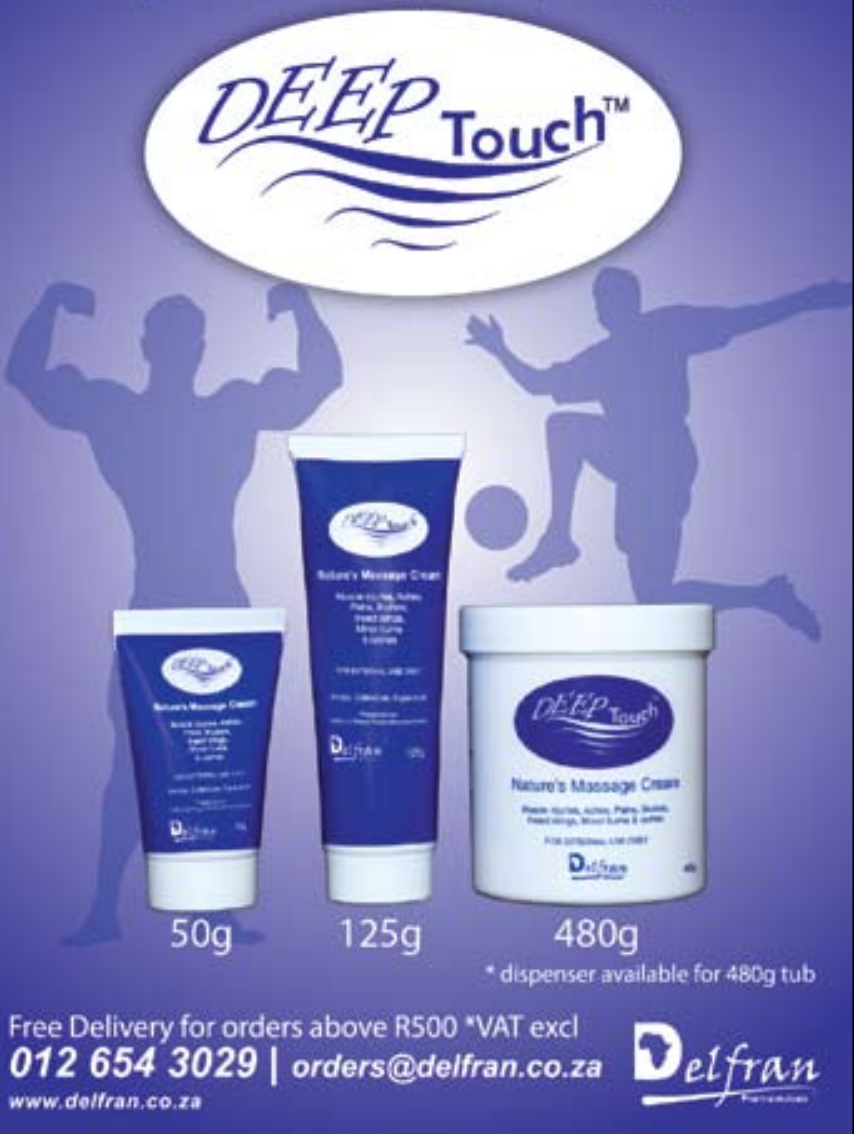

